\title{
LAS RELACIONES ENTRE HISTORIADORES DEL ARTE Y DEMÁS ESPECIALISTAS DE LA CONSERVACIÓN Y RESTAURACIÓN
}

\author{
Gabriel Ferreras Romero \\ Historiador del Arte
}

El motivo de este artículo invita a todo historiador del arte - $\mathrm{O}$ arqueólogo- a un examen de conciencia. Su papel y su responsabilidad en la conservación y restauración de los bienes culturales vienen en función de un trabajo en equipo, donde intervienen actualmente varios técnicos y científicos (arquitectos, ingenieros, químicos, restauradores, físicos, biólogos, geólogos, etc.) y donde el historiador no es nunca el ejecutante.

La importancia del papel que el historiador del arte está impulsado a interpretar es el resultado inmediato de la naturaleza misma de la restauración. Como lo ha señalado Césare Brandi, la restauración es, en efecto, "un problema crítico antes que llegar a ser un problema técnico". Determinar lo que debe ser conservado y restaurado, es primero conocer la obra de arte en su individualidad, el documento en su significación propia; es pues en principio y esencialmente plantear un problema de crítica histórica y estética, problema que resulta esencialmente de la competencia del historiador del arte o del arqueólogo. La función de éstos deberá pues consistir en intervenir para asegurar lo que se haga, y que ello se haga en tal sentido.

Ocurre que la intervención del historiador del arte y del arqueólogo es requerida bajo diversas formas y en una serie de sectores:

Para suscitar y mantener el interés de las obras en cuestión y para la educación del público en general.

Para asegurar una información completa y racional sobre la existencia y el estado de las obras para su inventarización y catalogación.

Para asegurar la documentación bibliográfica, de archivo y gráfica.

Pero sobre todo, el historiador del arte deberá intervenir para mantener en las intervenciones de restauración el problema crítico que le confiere su significación real. El historiador debería aquí representar la conciencia histórica y crítica que por razones evidentes de formación hace frecuentemente fallar a los demás técnicos: arquitecto, restaurador, químico, etc.; y esto, en el desarrollo de los trabajos, pero también en contribución bajo este ángulo en la formación especial de los técnicos y científicos que se orientan hacia la restauración.

Es evidente que la licenciatura universitaria no cualifica aún suficientemente al historiador del arte o al arqueólogo para permitirle asumir estas responsabilidades.

Como para el arquitecto, el químico, el artesano, la restauración es para el historiador del arte una especialización; ella exige una preparación particular.

En efecto, la operación de restauración se hace sobre la materia, y es a partir del estado material del objeto desde donde el historiador del arte o arqueólogo toma conocimiento de los datos en su problema crítico. Si no se puede descifrar el estado material no podrá por sí mismo plantear su problema en términos concretos. Es pues esencial que para asumir sus responsabilidades de crítica, él adquiera un mínimo de conocimientos tecnológicos que le permitan establecer el informe entre el aspecto o estética de una obra y su estructura material; de ahí la necesidad de ciertos conocimientos de los materiales y su comportamiento, y de la historia de las técnicas. Recordemos que las polémicas derivan simplemente de una información insuficiente a este respecto, se tratará de las diferencias entre historiadores del arte a propósito de las restauraciones, o de los informes entre los historiadores y los restauradores.

La inconsciencia del problema -desgraciadamente frecuente- entraña en principio una división radical entre el aspecto histórico y estético de una parte, y técnica y material de otra, como consecuencia estas actitudes características: tratar al restaurador como ejecutante, o aún estos dos extremos: confianza ciega o desconfianza a priori cara al técnico y al laboratorio. De ahí conductas culpables por las que el historiador del arte, el conservador del museo, o el arqueólogo se sustraen de sus responsabilidades, porque ellos eluden el verdadero problema concreto de la restauración: el diálogo con los especialistas de otras disciplinas que tienen sus colaboradores designados, porque ellos refuerzan la confrontación del aspecto y de la estructura material donde se concretiza toda la intervención de restauración.

Sería fácil multiplicar aquí los ejemplos que trataran el problema de la limpieza de las pinturas. Algunas están ligadas tanto a cuestiones sobre los barnices, las veladuras, la pátina o de la policromía de las esculturas donde el análisis estilístico debe venir a apoyar el análisis estratigráfico. La confron- 


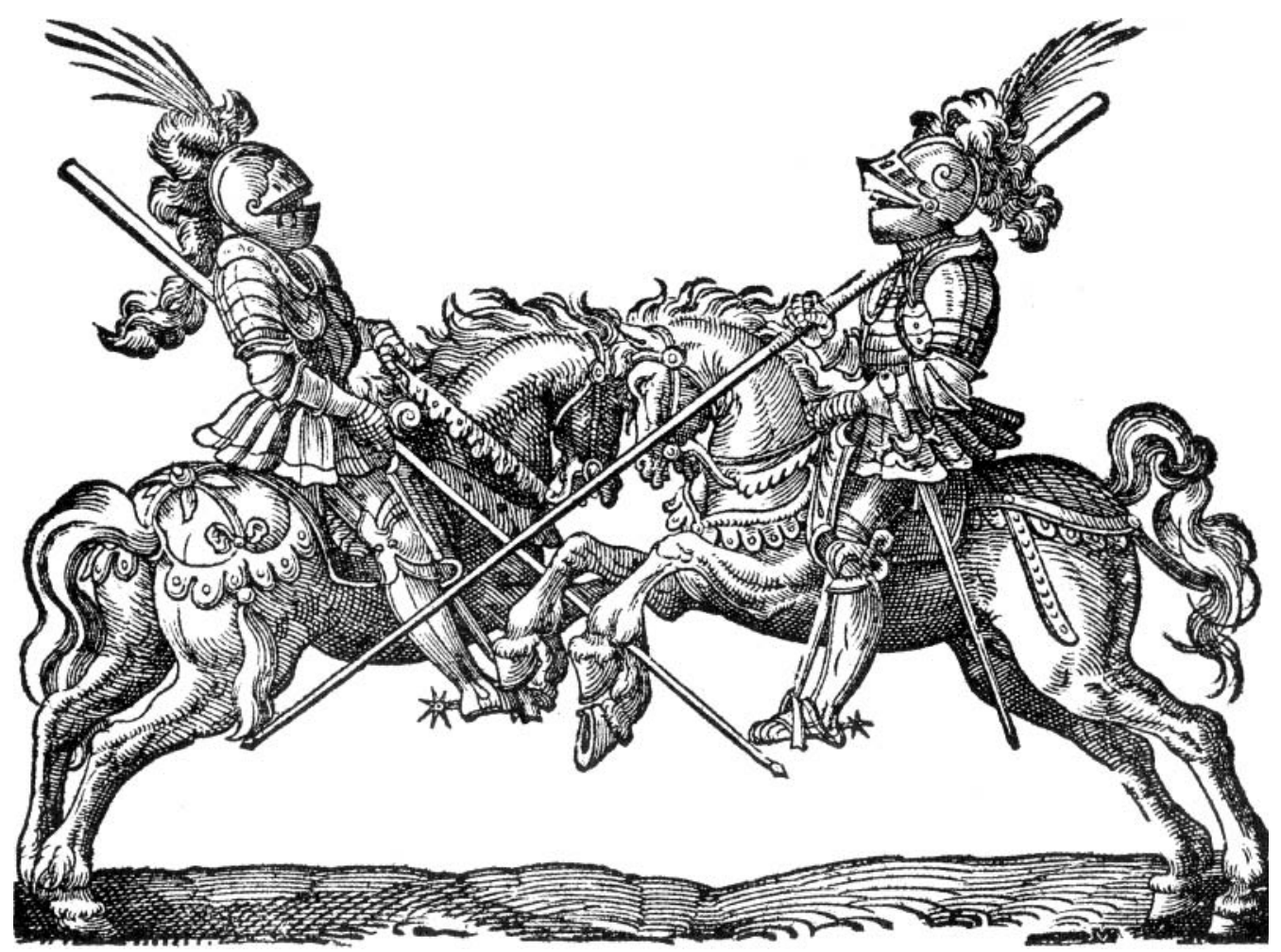

tación es la prueba verdadera del juicio crítico y ayuda a afirmarlo. Aspecto y estructura son de hecho indisolubles.

La necesidad de diálogo con los técnicos (restauradores, arquitectos) y los laboratorios (químicos, físicos, geólogos, biólogos, etc.) es por otra parte difícil por el hecho de que cada uno habla una lengua diferente y es desde luego necesario que exista un lenguaje común.

Esto entraña nuevas obligaciones para cada uno, y para el historiador en particular. Pero lo esencial será siempre su aspecto: así el color, por ejemplo, será un resultado tonal, un efecto cromático, etc.; para el restaurador es también una materia manipulada su reacción al pincel en la aplicación, una cierta dosificación en la mezcla, etc.; para el laboratorio, es en principio una estructura físico-química: el color es un fenómeno óptico, y la pintura un complejo de mezclas (pigmentos y aglutinantes, etc.).

Asegurar el reencuentro de estos diferentes planos es uno de los problemas, y no el menos arduo, de la restauración. Pero en este diálogo está todo el problema de la restauración que es aludido o mal planteado. La colaboración indispensable se fragmenta entonces en yuxtaposición de sectores impermeables que se reafirman sobre ellos mismos y marcan la problemática concreta. El historiador del arte se retira a su torre inexpugnable de su gusto, que lo identifica muy fácilmente a la gracia recibida del Arte, y sigue replegándose sobre los documentos tradicionales, el artesano sobre las fórmulas de su bien saber-hacer, el químico sobre su trabajo de investigación.
Hay por tanto que crear comprensión y confianza recíprocas, viviendo de forma paralela los departamentos de investigación, talleres y laboratorios. A cada uno le corresponde hacer algo. Pero sobre todo o particularmente al historiador y al arqueólogo, ya que es verdad que la significación misma de la restauración está por excelencia en su campo, puesto que se trata de la reactivación en el presente de la obra del pasado. Volvemos así pues a la formación de cada uno de los especialistas interesados: si el técnico restaurador, artesano, arquitecto y los científicos en general debieran ser iniciados en los problemas históricos y estéticos para enseñar a situar su intervención en la perspectiva concreta inversamente el historiador del arte y el arqueólogo deberían ser iniciados en cuestiones técnicas (interpretar una radiografía, reflectografía I. R., ultravioletas, estratigrafías, etc.), para poder plantear sus propios problemas en términos rigurosos y unir con los primeros en diálogo constructivo.

Actualmente los museos y los servicios de conservación son progresivamente más consciente a estas realidades, pero las universidades donde nos hemos formado historiadores y arqueólogos parece aún muchas veces ignorarlos. El ICOM reúne periódicamente después de varios años conservadores, restauradores y especialistas de laboratorios para favorecer esta difícil interpretación de las disciplinas. Un esfuerzo paralelo merecería ser hecho por parte universitaria, y la incorporación al programa de los estudios de Historia del Arte y Arqueología de algunas asignaturas de nociones técnicas, lo que podría tener en este sentido un efecto más favorable.
El bistoriador deberá

representar la conciencia bistórica y crítica que por razones de formación bace frecuentemente fallar a los demás técnicos:

arquitecto, restaurador, químico, etc., en el desarrollo de los trabajos, pero también en la contribución en la formación especial de los técnicos y científicos que se orientan bacia la restauración. 